\title{
A Adoção dos Controles Internos em uma Organização do Terceiro Setor como Sustentabilidade Econômica: Um Estudo de Caso em uma Associação de Minas Gerais
}

\section{The Adoption of Internal Control in a Third Sector Organization as Economic Sustainability: A Case Study in a Association of Minas Gerais}

\section{Lívia Maria de Pádua Ribeiro}

Doutoranda em Administração pela Universidade Federal de Lavras

Endereço: Rua Açucenas, 133, Apto 101, Nova Suissa

CEP: 30.460-020 - Belo Horizonte/MG - Brasil

E-mail: livia.padua@ig.com.br

Telefone: (31) 8859-2693

\section{Adriana Conceição Timóteo}

Graduada em Ciências Contábeis pelo Centro Universitário de Belo Horizonte - UNI-BH

Endereço: Rua Antônio Dias, 211, Bom Pastor

CEP: 35.500-163, Divinópolis/MG - Brasil

E-mail: adriana.timoteoct@ yahoo.com.br

Telefone: (31) 9301-4580

Artigo recebido em 17/11/2011. Revisado por pares em 07/05/2012. Reformulado em 28/05/2012. Recomendado para publicação em 19/06/2012 por Sandra Rolim Ensslin (Editora Científica). Publicado em 28/06/2012. 


\title{
Resumo
}

O presente artigo tem como objetivo principal verificar a contribuição do sistema de controles internos para a sustentabilidade econômica de uma Associação de apoio a crianças e jovens no estado de Minas Gerais. Para a realização desta pesquisa foram feitas visitas à Associação, análise de documentos e entrevista com a diretoria executiva, funcionários das áreas financeira e administrativa. Observou-se que a ausência de alguns controles facilita a fraude, os erros e os desperdícios de recursos físicos e financeiros. Já os controles internos existentes contribuem para o melhor aproveitamento e distribuição dos recursos, além de uma maior transparência das ações desenvolvidas proporcionando uma sustentabilidade econômica da Associação.

Palavras-chave: Controles internos. Terceiro setor. Sustentabilidade econômica.

\begin{abstract}
This article aims to determine the contribution of the main system of internal controls for the economic sustainability of an Association to support children and youth in the State of Minas Gerais. For this research was made visits to the Association, document analysis and interviews with senior management, employees of the financial and administrative. It was observed that the absence of some controls facilitates fraud, errors and waste physical and financial resources. Already the existing internal controls contribute to a better utilization and distribution of resources, and greater transparency of actions taken by providing an economic sustainability of the Association.
\end{abstract}

Keywords: Internal controls. Third sector. Economic sustainability.

\section{Introdução}

Diante do crescimento do Terceiro Setor, aumenta a demanda por novos métodos de trabalho e por adoção de controles internos nas organizações visando a uma eficiência da gestão e dos resultados, além de uma transparência das ações desenvolvidas. Sabe-se que as organizações que compõem o Terceiro Setor não visam ao lucro, mas buscam atender às necessidades da sociedade, de forma geral, no que se refere à educação, ao lazer, à cidadania, ao meio ambiente, dentre outros. $\mathrm{O}$ fato de serem organizações sem fins lucrativos não quer dizer que não buscam por uma sustentabilidade econômica. Se as organizações do Terceiro Setor não fizerem uma boa gestão adotando controles internos, elas não conseguem cumprir sua missão e permanecer no mercado. Além disso, as organizações que não possuem controles internos terão dificuldade de apresentar uma prestação de contas para os órgãos públicos e demonstrar os seus resultados para a sociedade, perdendo a transparência das ações desenvolvidas. As organizações do Terceiro Setor, também denominadas de "entidades sem fins lucrativos", necessitam de controles no que se refere ao destino dado aos recursos públicos e doações recebidas. Contudo, os controles internos também são necessários para um melhor aproveitamento e distribuição dos recursos implicando um maior benefício para a 
sociedade.

Em busca da sustentabilidade econômica e da transparência das ações desenvolvidas pelas organizações, se faz necessário a adoção de controles internos. Estes contribuem para eliminar desperdícios, evitar fraudes e erros, apoiar nas decisões gerenciais e, muitas vezes, aperfeiçoar a qualidade das tarefas. Pode-se entender como controle interno qualquer instrumento da organização que se destina à fiscalização, vigilância e verificação administrativa, permitindo dirigir, observar e prever acontecimentos. Os controles internos podem ser divididos em controles administrativos e controles contábeis. Para Perez Jr. (2006), os controles internos administrativos são como um plano da organização, ou seja, são todos os métodos e procedimentos relacionados com a eficiência operacional, bem como o respeito e a obediência às políticas administrativas; já os controles internos contábeis, para Lopes de Sá (2002), são os que estão relacionados com a proteção dos ativos, com as demonstrações contábeis e com a validade dos registros contábeis.

Neste artigo, pretendeu-se destacar a importância dos controles internos como sustentabilidade econômica para as organizações do Terceiro Setor. Com esta pesquisa, buscou-se estudar os controles internos administrativos e contábeis, realizando um estudo de caso em uma Associação de Minas Gerais que visa promover a educação e apoio às crianças e aos jovens da comunidade local. A Associação em estudo possui um programa com ações complementares à escola para manter crianças e jovens em lugar adequado e seguro, visando desenvolver habilidades e atitudes que contribuem para formação de cidadãos com valores éticos e morais.

O objetivo principal deste artigo foi verificar a contribuição do sistema de controles internos para a sustentabilidade econômica de uma Associação de apoio a crianças e jovens no estado de Minas Gerais. E como objetivos específicos, o estudo buscou: (i) analisar a estrutura organizacional e as atividades desenvolvidas pela associação; (ii) realizar diagnóstico em relação à necessidade de Controles Internos visando à sustentabilidade econômica; e (iii) confrontar com os controles internos existentes. Sendo assim, a pesquisa tem o seguinte questionamento: Qual a contribuição dos controles internos para a sustentabilidade econômica de uma Associação de apoio a crianças e jovens?

Este artigo está dividido em cinco seções, incluindo esta introdução. A segunda seção apresenta o referencial teórico que trata do Terceiro Setor e a sustentabilidade; e os tipos de controles internos adotados por uma organização em busca da eficiência da gestão. A terceira seção apresenta a metodologia de pesquisa utilizada para a realização deste estudo. A quarta seção consiste em descrever as discussões e os resultados da pesquisa. E, por fim, a quinta seção realiza as considerações deste estudo, apresentando suas limitações, as sugestões para futuras pesquisas e suas conclusões.

\section{Referencial Teórico}

Nesta seção, foi discutido sobre o surgimento e as características do Terceiro Setor, enfatizando a relevância da sustentabilidade econômica para as organizações sem fins lucrativos. Mesmo a organização que não tem como foco o lucro deve se preocupar com a sustentabilidade econômica para a sua permanência no mercado e cumprimento da sua missão social. 
Os controles internos apresentam-se como ferramenta para o sucesso da sustentabilidade econômica. Sendo assim, esta seção também abordou os tipos de controles internos importantes para uma boa gestão, um melhor aproveitamento dos recursos e sustentabilidade econômica da organização.

\title{
2.1 O Terceiro Setor e a Sustentabilidade
}

As organizações que compõem o Terceiro Setor não são novas, segundo Salvatore (1998), existem desde o Brasil Colônia, aliadas à Igreja Católica. Porém, a forma de interpretá-las como um "setor" é nova. Para Fischer (2002), ao ser considerado como um "setor", pleiteia-se a igualdade em relação ao "Primeiro Setor", representado pelo Estado, e o "Segundo Setor", representado pelas empresas privadas. Essa nova colocação do "Terceiro Setor" surgiu a partir dos anos noventa, do século XX, ganhando a visibilidade na sociedade com a inserção das organizações não governamentais (ONGs) e com a proposta de parceria intersetorial.

\begin{abstract}
Nesse contexto, as alianças intersetoriais são as relações de colaboração estabelecidas entre duas ou mais organizações, cada qual inserida em um dos três setores. Essas alianças são constituídas para elaborar e implementar projetos e programas que visam beneficiar uma comunidade, erradicar ou minimizar algum problema social, atender as necessidades de grupos carentes ou divulgar e defender uma causa de interesse público (FISCHER, 2005, p. 12).
\end{abstract}

A concessão de alguns benefícios do Poder Público, como imunidade e isenção de impostos e contribuições, estimula a criação de novas associações, fundações, ONGs, dentre outras organizações que compõem o Terceiro Setor. Além disso, essas organizações possibilitam o recebimento de recursos públicos, por meio de convênios, contratos, subvenções sociais e termos em parceria (CONSELHO FEDERAL DE CONTABILIDADE, 2008).

As parcerias e alianças estratégicas de diversos segmentos sociais contribuem para a concretização das ações desenvolvidas pelo Terceiro Setor. Contudo, a competência para gerir os recursos e alcançar a sustentabilidade econômica da organização depende da adoção de controles internos. Um dos desafios do Terceiro Setor é a forma de gerir os recursos financeiros e humanos que estão dentro da organização.

Quando se trata do Terceiro Setor, a sustentabilidade é enfatizada no âmbito social. Sustentabilidade é a qualidade de se manter para sempre. No entanto, a sustentabilidade pode ser baseada no tripé: econômico, social e cultural (VALADÃO JR; MALAQUIAS; SOUSA, 2008). É o foco deste estudo a sustentabilidade econômica em uma organização do Terceiro Setor.

Para uma melhor compreensão, apresenta-se o Quadro 1, adaptado de Valadão Jr., Malaquias e Sousa (2008), com a definição das categorias de sustentabilidade por Sachs e os indicadores que demonstram a sustentabilidade econômica.

Quadro 1 - Categorias, definição constitutiva e indicadores de sustentabilidade

\begin{tabular}{|l|l|l|}
\hline Categorias & Conceitos propostos por Sachs & Indicadores \\
\hline Sustentabilidade Econômica & - Alocação eficiente dos recursos & Definição de Metas e Objetivos \\
\hline
\end{tabular}


A Adoção dos Controles Internos em uma Organização do Terceiro Setor como Sustentabilidade Econômica:...

\begin{tabular}{|c|c|c|}
\hline & \multirow{7}{*}{$\begin{array}{l}\text { - Fluxo constante de investimentos } \\
\text { públicos e privados }\end{array}$} & Existência de política para a qualidade \\
\hline & & Gerenciamento de riscos e crises \\
\hline & & Auditorias internas e externas \\
\hline & & Infraestrutura adequada \\
\hline & & Satisfação dos atendidos \\
\hline & & $\begin{array}{l}\text { Gestão e monitoramento de processos, } \\
\text { produtos e serviços }\end{array}$ \\
\hline & & Avaliações dos resultados da ONG \\
\hline \multirow{5}{*}{ Sustentabilidade Social } & \multirow{5}{*}{$\begin{array}{l}\text { - Criação de um processo de } \\
\text { desenvolvimento sustentado para uma } \\
\text { sociedade justa pela geração de } \\
\text { emprego e renda }\end{array}$} & Geração de emprego e renda \\
\hline & & $\begin{array}{l}\text { Capacitação e desenvolvimento de } \\
\text { pessoas }\end{array}$ \\
\hline & & $\begin{array}{l}\text { Programa de saúde e segurança dos } \\
\text { desenvolvidos }\end{array}$ \\
\hline & & Sistema de trabalho socialmente aceito \\
\hline & & Integração com a sociedade \\
\hline \multirow{5}{*}{ Sustentabilidade Cultural } & \multirow{5}{*}{$\begin{array}{l}\text { - Processo de desenvolvimento com } \\
\text { raízes endógenas } \\
\text { - Capacidade de manter a diversidade } \\
\text { de culturas e valores }\end{array}$} & Aprendizagem organizacional \\
\hline & & $\begin{array}{l}\text { Existência de código de conduta } \\
\text { organizacional }\end{array}$ \\
\hline & & $\begin{array}{l}\text { Adequação a comunicação interna e } \\
\text { externa }\end{array}$ \\
\hline & & Imagem Organizacional \\
\hline & & Análise crítica pela organização \\
\hline
\end{tabular}

Fonte: Valadão Jr; Malaquias; Sousa (2008, p. 137)

O Quadro mostra que existem indicadores que relatam como está a sustentabilidade da organização, seja econômica, social ou cultural. Na sustentabilidade econômica, observa-se que as avaliações dos resultados, a gestão dos processos, o gerenciamento de riscos e as auditorias internas e externas, dentre outros, indicam como a organização se encontra quando se trata de valores econômicos e financeiros. Por isso, neste estudo, o controle interno apresenta-se como uma ferramenta para identificar se a organização tem caminhado ou não em direção à sustentabilidade econômica, lembrando que a proposta deste estudo é verificar a contribuição do sistema de controles internos para a sustentabilidade econômica de uma Associação de Minas Gerais. A partir desta pesquisa, é possível compreender se a Associação em estudo possui controles internos que contribuem para a sustentabilidade econômica ou se ela precisa fortalecer e implementar outros controles. Portanto, o próximo assunto a ser abordado é sobre os tipos de controles internos adotados por uma organização em busca da eficiência da gestão.

\subsection{Controles Internos}

Mattos e Mariano (1999) explicam que controle interno é um significado bastante amplo. Entre vários conceitos, os autores apresentam uma síntese das ideias principais acerca 
do tema: "controle interno é o conjunto de medidas adotadas pela empresa com o intuito de proteger o seu patrimônio, fornecendo registros contábeis fidedignos, possibilitando uma correta tomada de decisão" (MATTOS; MARIANO, 1999, p. 34).

Segundo o Comitê de Procedimentos de Auditoria do Instituto Americano de Contadores Públicos Certificados (AICPA), citado por Migliavacca (2004), os controles internos compreendem o plano de uma organização, o conjunto de procedimentos, métodos ou rotinas. Os controles internos são adotados para proteger o patrimônio, verificar os registros contábeis, promover a eficiência operacional e contribuir para encorajar a política traçada pela administração da organização. Os autores Anthony e Govindarajan (2008) complementam que os controles internos são adotados com o objetivo de evitar fraudes, erros, ineficiências e crises nas organizações.

Para Attiê (2007), a confiabilidade dos resultados gerados por procedimentos, ou seja, por controles internos, pode também ser usada para tomada decisão. É necessário que a organização tenha organograma, manuais de procedimento e que o plano organizacional seja dividido em setores e funcionários com os níveis de responsabilidade e autoridade definidas. Perez Jr. (2006) explica que o sistema de controle é composto por controles internos de natureza contábil e administrativa. Além disso, Perez Jr. (2006) menciona que o controle pode ser prévio, durante e após o fato. O controle prévio ocorre a partir da projeção dos dados reais e a comparação dos resultados prováveis contra aqueles que se pretendem atingir. $\mathrm{O}$ controle durante o fato é o controle do momento da ocorrência de desvios, fraudes ou falhas. E já o controle após o fato pode ser adotado para reparar ou tomar medidas para que o fato semelhante não venha ocorrer.

Conforme havia dito Lopes de Sá (2002), os princípios éticos e a integridade dos colaboradores são indispensáveis para o fortalecimento da sustentabilidade econômica de uma organização. Os controles internos são a chave para descobrir manipulações e conluios que infringem a ética e quebram toda a sustentabilidade de uma organização.

\subsection{Tipos de Controle Interno}

O controle interno, segundo Pereira (2004), favorece o processo de gestão não apenas quanto à prevenção de fraudes. Para o autor, outra função considerada a mais importante é a sua contribuição informativa que apoia a gestão na tomada de decisões. Para Pereira (2004), o controle interno tem como objetivo a potencialização do êxito no processo decisório, o que implica maior geração de benefícios sócio-econômicos e também interfere em retornos sociais e ambientais. O controle interno ultrapassa as barreiras do retorno financeiro (PEREIRA, 2004).

\section{Controle de Estoque}

O controle de estoque é de suma importância na gestão de uma organização, pois, por meio dele, poderá administrar melhor o que entra e sai de uma organização, seja matériaprima, mercadorias ou materiais de consumo. Segundo Pascoal (2008, p. 12), "O gerenciamento de estoque surgiu para suprir uma necessidade das organizações de controlar tudo que se passava com os materiais, o período de cada um dentro dos armazéns, a quantidade mantida em cada compartimento, quando pedir novamente aquele produto". Em uma organização do Terceiro Setor, esse controle se faz necessário para se ter o controle dos

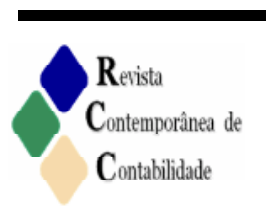


materiais a ser consumido e quando realizar a reposição. O controle pode ser importante também quando o material ou o alimento for perecível. Os controles podem acontecer em fichas manuais ou por meio da tecnologia, desenvolvendo planilhas, ou utilizando software específico.

\section{Controle do Imobilizado}

De acordo com Marion (2004, p. 66), “Ativo imobilizado são bens destinados manutenção da atividade principal da empresa ou exercidos com essa finalidade". Os bens que auxiliam a organização na consecução de sua atividade pertencem ao ativo imobilizado: máquinas, equipamentos, prédio (em uso), ferramentas, móveis e utensílios, instalações, veículos, etc.

Almeida (2008) explica que o controle do imobilizado é o controle dos bens patrimoniais e este é feito usando informações relativas de cada um: valor de compra ou avaliação; localização deste bem na organização, descrição e especificações relacionando-o com um código.

\section{Controle de Contas a Pagar}

O conceito de contas a pagar é em si muito simples. Significa o dinheiro que a empresa deve em contas e obrigações. Nessa conta, estão incluídas dívidas contraídas com fornecedores, obrigações com o fisco, com prestadores de serviços e outras saídas previstas de dinheiro. Para Gitman (2004), as contas a pagar representam a principal fonte de financiamento em curto prazo.

Os processos de controle de contas a pagar devem ser transparentes e atualizados para que assim as despesas ou gastos sejam pagos no momento adequado, não gerando juros à organização e nem problemas jurídicos.

\section{Controle de Contas a Receber}

O Controle de Contas a Receber representa o crédito da organização com seus clientes. E esses créditos configuram-se, principalmente, no recebimento das vendas, revendas ou serviços prestados. Já em uma organização do Terceiro Setor, os recebimentos dizem respeito aos recursos públicos ou às doações que são realizadas por meio de convênios, subvenções sociais e termos em parceria (CONSELHO FEDERAL DE CONTABILIDADE, 2008).

\section{$>$ Conciliação}

A conciliação é um comparativo entre as movimentações existentes em uma conta bancária e as existentes no controle financeiro. Geralmente a conciliação é elaborada tomando como base o último dia do mês e consiste em eliminar as transações que aparecem em ambos os registros. Franco e Marra (2004) afirmam que as conciliações bancárias deverão ser integralmente revisadas ou refeitas quando existir auditoria na organização, de maneira que se assegure de que não haja erros.

\section{Controle Orçamentário}

Orçar quer dizer calcular, avaliar e estimar. Portanto, orçamento na organização é o instrumento utilizado para estimativas, avaliações, cálculos, previsões, feitos de forma 
antecipada com o intuito de se mensurar a melhor forma de atingir o objetivo prédeterminado. Segundo Padoveze (2004, p. 501), "O orçamento é uma ferramenta de controle por excelência de todo o processo operacional da empresa, pois, envolve todos os setores da companhia".

O orçamento tem o papel de auxiliar a visualização do comportamento das variáveis planejadas por meio de relatórios quantitativos ao longo do tempo. É o instrumento que pode identificar possíveis gargalos e pontos críticos nos processos da organização e elaborar planos para eliminar ou minimizar o seu efeito. A organização que elabora o orçamento consegue obter melhores resultados do que aquelas que não o fazem, uma vez que se planeja o futuro e se tem a previsão dos gastos para cada setor. Esse controle orçamentário contribui para que a função do "controle interno", que, segundo Pereira (2004), reside em potencializar as informações para a tomada de decisões em uma gestão.

\section{Fluxo de Caixa}

O fluxo de caixa serve para informar a origem do dinheiro que entrou e saiu do caixa de um dado período, seja diário, semanal ou mensal. De acordo com Marion (2004, p.110), "todo mundo tem seu fluxo de caixa, por mais simples que seja". O fluxo de caixa é composto de dados obtidos dos controles de contas a pagar, contas a receber, de despesas, de saldos de aplicações e de todos os demais que representem as movimentações de recursos financeiros disponíveis da organização.

\section{Técnicas de Análise de Investimentos}

A análise de investimentos é relevante para que a organização escolha a melhor alternativa para se investir, propiciando uma maior rentabilidade com o menor custo. Para Assaf Neto (2009), uma determinada organização pode ter um conjunto de projetos de investimentos em diferentes momentos de execução. O objetivo da organização é avaliar as alternativas de investimento de forma a promover o incremento de sua riqueza líquida.

Em princípio, análise de investimento parece não ser uma técnica usada pelo Terceiro Setor, uma vez que, na maioria das vezes, não apresentam recursos para serem aplicados. Contudo, as organizações podem ter momentos de aplicação de recursos para posteriormente realizarem os gastos com a sua missão. Essas organizações devem estar atentas aos investimentos a curto e médio prazo.

Pereira (2004) explica que existem duas visões ao observar o controle interno: uma com foco antifraude; e a outra, com o foco em gestão. Percebe-se que essa técnica de análise de investimento está voltada para a segunda visão: a de gerenciamento e eficácia da organização.

\section{$>$ Análise das Demonstrações Contábeis}

Para Padoveze (2004, p. 191), a análise das demonstrações contábeis "Constitui-se num processo de meditação sobre os demonstrativos contábeis, objetivando uma avaliação da situação da empresa, em seus aspectos operacionais, econômicos, patrimoniais e financeiros". E, segundo Matarazzo (2003), os indicadores econômico-financeiros, extraídos das demonstrações contábeis, servem para a tomada de decisão da organização. Percebe-se que as organizações do Terceiro Setor estão em busca da realização das análises das demonstrações

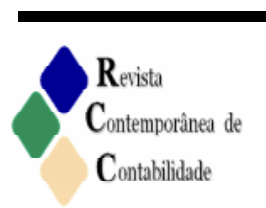


contábeis, uma vez que a sua preocupação ainda é o fornecimento desses relatórios de forma regular.

\begin{abstract}
As demonstrações contábeis preparadas para as entidades em fins lucrativos devem fornecer informações de forma regular e tempestiva; possibilitar o acesso do usuário da informação aos objetivos, estrutura e atividades executadas pelas entidades; e possibilitar o usuário uma apreciação das transações realizadas durante o exercício social das Entidades de Interesse Social, bem como uma posição contábil no final do ano (CONSELHO FEDERAL DE CONTABILIDADE, 2008, p. 60).
\end{abstract}

Martin (2002) explica que as organizações precisam incorporar novas dimensões e novos instrumentos com a finalidade de fornecer informações para os administradores atingirem os seus objetivos de modo mais eficaz e eficiente. Essas transformações, segundo Martin (2002), levaria a adoção da controladoria.

\title{
$>$ Controle Tributário
}

Esse controle tem como objetivo, controlar os cálculos dos tributos na organização. Trata-se de uma ferramenta que controla os impostos executados e a emissão de guias. No caso de uma organização do Terceiro Setor, é necessário atentar à legislação que concede imunidade e isenção de grande parte desses impostos e contribuições. Conforme Oliveira et al. (2010), o controle tributário exige conhecimento técnico e estudo prévio para que a organização como contribuinte faça a opção pela alternativa menos onerosa. O controle permite uso de formas lícitas para reduzir o seu pagamento de tributos ou em alguns casos até mesmo extinguir o pagamento se a organização for isenta. É bom ressaltar que a isenção do pagamento muitas vezes não extingue as obrigações acessórias.

Martin (2002) ressalta que a Contabilidade não pode ser um modelo exclusivamente financeiro, pois, dessa forma, não consegue oferecer informações necessárias para dar apoio à gestão das organizações na sua tomada de decisões. Os controles tributários, por exemplo, não podem ser baseados somente nas declarações, e as organizações precisam elaborar o seu planejamento tributário.

\subsection{Estudos sobre os Controles Internos Aplicados nas Organizações}

Diversas pesquisas que tratam sobre os controles internos, como, por exemplo, os estudos de Albuquerque (2011); Azevedo, Ensslin e Reina (2010); Lunkes (2008) demonstram a importância do controle interno e destacam que a ausência destes ou a sua aplicação inadequada refletem nos resultados das organizações e na qualidade dos serviços prestados por elas. Esses estudos foram realizados em diversos tipos de organizações e mencionam a relevância de aprimorar os controles internos para melhorar a eficiência das operações. Na pesquisa realizada por Albuquerque (2011), o autor evidencia a importância do controle interno governamental ao estudar uma instituição pública do ensino superior. No trabalho desenvolvido por Azevedo, Ensslin e Reina (2010), com a finalidade de verificar a existência e a atuação dos controles internos de cinco Fundações de Amparo à Pesquisa da Universidade Federal de Santa Catarina, apenas três Fundações apresentaram um órgão de controle, além de serem constatados nas Fundações analisadas, que alguns procedimentos de controles não eram aplicados. Os estudos de Lunkes (2008), realizados em empresas 
hoteleiras, demonstram que os controles internos ainda são utilizados em uma quantidade reduzida pelas organizações em seu processo de gestão.

Contudo, outros estudos têm revelado que as organizações já estão adotando controles internos com menor deficiência, apresentando uma tendência a criar e gerar controles com intuito de monitorar tarefas e aumentar a qualidade das informações. Podem ser citados os estudos realizados por Silva, Rocha e Melo (2011) em cento e doze escritórios de Contabilidade, além da pesquisa realizada por Silva Maia et al., (2005) na General Electric Brasil. No primeiro estudo, é possível perceber que os controles internos contribuem para o aumento da qualidade e confiabilidade das informações fornecidas pelos escritórios de Contabilidade, ao gerar e enviar relatórios financeiros, contábeis e gerenciais para os seus diversos tipos de usuários. No segundo estudo, ao examinar a General Electric Brasil, os pesquisadores concluem que o modelo internacional de estrutura de controle interno, o Committee of Sponsoring Organization of the Treadway Comission (COSO), é aplicado adequadamente nessa organização contribuindo para a excelência corporativa.

Farias, Luca e Machado (2009) investigaram a adequação da metodologia COSO no gerenciamento dos controles internos do Banco do Brasil. A pesquisa demonstra que os controles internos do Banco do Brasil é alinhado com o interesse da estrutura e da cultura proposta pela própria instituição financeira. $\mathrm{O}$ controle interno é um processo que aprimora a gestão estratégica das empresas.

No trabalho desenvolvido por Martin, Santos e Dias Filho (2004), os controles internos são apontados como instrumentos da governança e as bases do chamado novo modelo de Controladoria. Para os autores, sem um sistema de controle de custódia e desempenho, não poderia haver uma governança efetiva.

\section{Metodologia}

Esta seção buscou esclarecer métodos e procedimentos para a realização desta pesquisa. Para uma melhor compreensão da metodologia, a seção está subdividida em: classificação da pesquisa; caracterização da Associação investigada; procedimentos para coleta e tratamento dos dados.

\subsection{Classificação da Pesquisa}

O sistema de controle interno da Associação localizada no Estado de Minas Gerais é o objeto da presente pesquisa. O tipo de pesquisa adotado pode ser classificado como exploratória e com uma abordagem qualitativa.

Para Vergara (2000), a investigação exploratória refere-se à pesquisa em uma área em que há pouco conhecimento acumulado e sistematizado sobre o assunto. Percebe-se, na literatura acadêmica, que os trabalhos existentes sobre o controle interno são na maioria relacionados às organizações privadas. Este estudo investiga a contribuição do sistema de controles internos para a sustentabilidade econômica de uma Associação de apoio às crianças e jovens no Estado de Minas Gerais. A pesquisa exploratória tem a característica de ser a primeira etapa de uma investigação mais ampla.

A abordagem qualitativa, segundo Oliveira (2004, p. 114), "é um tipo de pesquisa que não se tem a pretensão de medir ou numerar". Segundo Vergara (2000), a abordagem 
qualitativa não utiliza métodos e técnicas estatísticas e tem por finalidade a construção de um instrumento de pesquisa adequado à realidade.

\subsection{Caracterização da Associação Investigada}

Para a realização desta pesquisa foi feito um estudo de caso em uma Associação localizada no estado de Minas Gerais. A Associação visa promover a educação e apoio às crianças e aos jovens da comunidade local. A Associação em estudo possui um programa com ações complementares à escola para manter crianças e jovens em lugar adequado e seguro, visando desenvolver habilidades e atitudes que contribuem para a formação de cidadãos com valores éticos e morais. A Associação foi oficialmente fundada em 1999 e atualmente atende cerca de 250 crianças e jovens da comunidade local. A organização encontra-se com um quadro de 26 funcionários e 13 voluntários, como consta a seguir:

Quadro 2 - Relação de quantidades e cargos de funcionários da instituição

\begin{tabular}{|l|r|}
\hline \multicolumn{1}{|c|}{ Cargo } & \multicolumn{1}{c|}{ Quantidade } \\
\hline Monitores & 4 \\
\hline Instrutores & 6 \\
\hline Assistente de Tesouraria & 1 \\
\hline Cozinheira / Assistente & 2 \\
\hline Assistente Financeira & 1 \\
\hline Coordenador de Artes & 1 \\
\hline Assistente Administrativo & 2 \\
\hline Faxineira & 1 \\
\hline Educadora Social & 2 \\
\hline Estagiários & 2 \\
\hline Produtora de Executiva & 1 \\
\hline Workshop de Percussão & 1 \\
\hline Porteiro & 1 \\
\hline Coordenadora Pedagógica & 1 \\
\hline Total & $\mathbf{2 6}$ \\
\hline Fon: Elaborada pelos autores. & \\
\hline
\end{tabular}

Fonte: Elaborada pelos autores.

\section{Quadro 3 - Relação de quantidades de voluntários e cargos da instituição}

\begin{tabular}{|l|r|}
\hline \multicolumn{1}{|c|}{ Cargo } & \multicolumn{1}{c|}{ Quantidade } \\
\hline Presidente Diretor & 1 \\
\hline Vice Presidente & 1 \\
\hline Secretária & 1 \\
\hline Vice - Secretária & 2 \\
\hline Tesoureiro & 1 \\
\hline Vice - Tesoureiro & 1 \\
\hline Coordenadora Ambiental & 1 \\
\hline
\end{tabular}




\begin{tabular}{|l|r|} 
Conselheiro & 2 \\
\hline Conselheiro Suplente & 3 \\
\hline Total & $\mathbf{1 3}$ \\
\hline
\end{tabular}

Fonte: Elaborada pelos autores.

\subsection{Procedimentos de Coleta e Tratamento dos Dados}

Quanto às técnicas para a coleta dos dados, foram realizadas entrevistas com os funcionários da área administrativa e financeira, além de um voluntário da diretoria executiva. Foram realizados roteiros para orientar a entrevista. Diversas visitas foram feitas para conhecer a organização e seus controles internos. Nestas visitas, foram coletados documentos que serviram para realizar a discussão e apresentar os resultados da pesquisa.

Após a coleta de dados por meio das entrevistas, as mesmas foram transcritas e analisadas com a finalidade de responder ao questionamento dessa pesquisa e atingir os objetivos propostos nesse estudo.

\section{Discussão e Resultados}

A Associação de Minas Gerais, estudada nesta pesquisa, não possui um manual interno com as responsabilidades e as atribuições das funções de cada funcionário. Além disso, a Associação não possui um código de ética ou de conduta para os funcionários, podendo gerar dificuldades na gestão da organização. A Associação apresenta a seguinte divisão de departamentos: a secretaria/administração, o financeiro, a cozinha, a pedagogia e a informática. A Contabilidade da organização é terceirizada. Para um melhor entendimento dos departamentos da Associação foi elaborado um organograma (a Associação não possui um organograma), Figura 1.

Em relação ao funcionamento desses departamentos, verificou-se que toda a organização está centralizada no departamento "secretaria/administração", que tem apenas dois funcionários. A "secretaria/administração" recebe todas as notas fiscais, folha de pagamentos que são direcionadas para o departamento financeiro efetuar os pagamentos. A "secretaria/administração" elabora a ficha cadastral das crianças e jovens atendidas na Associação. As fichas são encaminhadas para o departamento de pedagogia realizar os relatórios de acompanhamentos dos educadores (instrutores e monitores) e apontar os materiais destinados às oficinas. A "secretaria/administração" controla a quantidade de crianças e jovens em cada atividade. É necessário realizar esse controle para não ocorrer superlotação em uma determinada atividade. O curso de informática, por exemplo, tem um limite devido à quantidade de computadores. A entrada e a baixa de gêneros alimentícios são realizadas também pela "secretaria/administração". Todo o operacional da Associação passa pela "secretaria/administração", o que sobrecarrega os funcionários e dificulta o processo de gestão.

No departamento financeiro foram identificados apenas dois controles internos, que são relatórios gerenciais que contribuem para um melhor aproveitamento dos recursos da organização: o controle caixa e o controle de contas a pagar. Além desses controles, existe um programa financeiro, o "MaxManager", que facilita a apuração dos custos com pessoal, porém não existe controle de gastos, custos e despesas com as crianças e jovens atendidos. A 
Associação não controla essa informação, tem apenas uma planilha com as estimativas dos gastos, mas tais planilhas não apresentam a realidade dos resultados. As planilhas de gastos estimados são realizadas apenas para apresentar aos órgãos públicos quando solicitado, e não há uma utilização para o processo de gestão e tomada de decisão da organização. Percebe-se que as informações contábeis não apresentam a realidade da Associação, pois os custos e despesas não são controlados diariamente, podendo não ser contabilizados e demonstrados no balanço da organização. A Associação possui um software que poderia ajudar em alguns procedimentos de controle interno e não é utilizado por falta de conhecimento e treinamento de funcionários.

Figura 1- Organograma da Associação

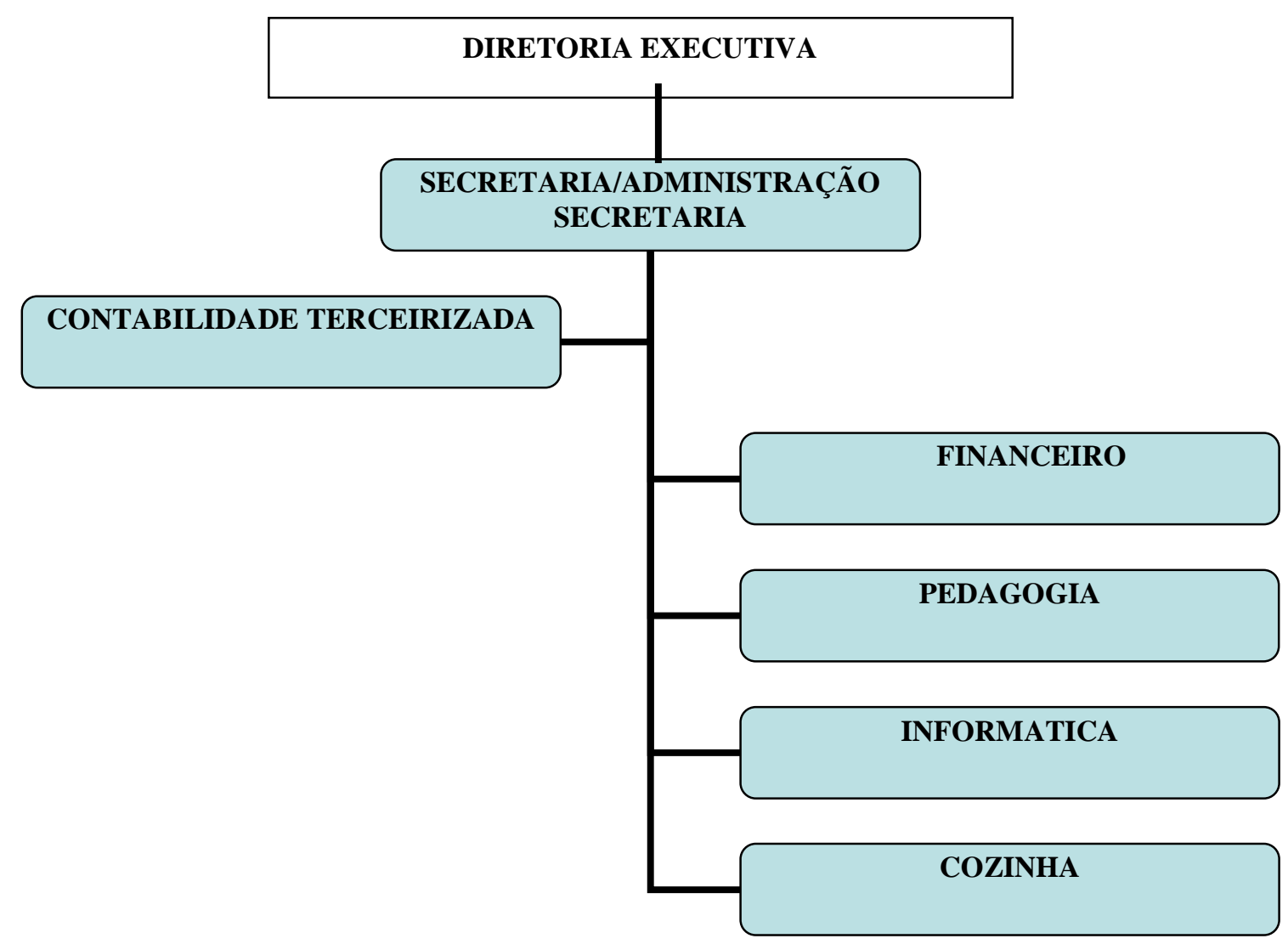

Fonte: Elaborada pelos autores.

Ao analisar o departamento "cozinha", verificou-se que existe um controle de estoque dos gêneros alimentícios. Para os demais materiais de consumo da cozinha, não há um controle interno. Um ponto positivo é a existência do controle de estoques de alimentos, uma vez que a organização tem o controle das saídas e entradas, o que facilita no momento da compra. Porém, não existe uma projeção de orçamento de compras para os materiais de consumo e dos gêneros alimentícios. Em relação ao imobilizado localizado na cozinha não existe um controle. 
Já no departamento de pedagogia observou-se a existência de um acompanhamento no que se refere ao ensino prestado pelos educadores às crianças e aos jovens. Nesse departamento, são realizados relatórios feitos pelos educadores e discutidos em conjunto com o setor responsável no acompanhamento do desenvolvimento das crianças e dos jovens. Contudo, não existe um controle dos materiais didáticos comprados pela Associação e usados pelas crianças e jovens.

No departamento de informática, há um acompanhamento nos horário das aulas de informática para as crianças e jovens da Associação e para as pessoas da comunidade, entretanto não possui o controle do imobilizado.

No que se refere a doações de ativo imobilizado, observou-se que não há um controle interno. As doações podem ser recebidas por qualquer funcionário e o bem não é identificado. O controle do imobilizado é de grande importância para a salvaguarda do patrimônio da Associação, além de separar os bens obsoletos dos bens duráveis com identificação de números e de fornecedores ou doadores, porém esse controle não existe na organização.

Em relação à contabilização de suas atividades operacionais, já foi mencionado que a Contabilidade é terceirizada. Os documentos e informações em relação à admissão e demissão são enviados pela "secretaria/administração". A Associação faz todas as declarações necessárias a serem repassadas aos órgãos públicos quando solicitado. A Associação não possui uma auditoria interna nos departamentos e não realiza todos os controles internos relevantes para sua sustentabilidade econômica, isso faz com que a Associação não aproveite os recursos de forma mais adequada.

Existe um controle do número de crianças e jovens atendidos por cada ciclo conforme as suas respectivas idades, e o número das crianças e jovens não frequentes diariamente na Associação, conforme mostra o Quadro 4.

Quadro 4 - Grupo de crianças e jovens

EDUCANDOS DA ASSOCIACẼ̃O 2010

\begin{tabular}{|l|c|c|}
\hline \multicolumn{1}{|c|}{ CRIANÇAS E JOVENS } & FAIXA ETÁRIA & QUANTIDADE \\
\hline I Ciclo & 6 a 8 anos & 28 \\
\hline II Ciclo & 9 a 12 anos & 63 \\
\hline III Ciclo & 12 a 18 anos & 48 \\
\hline Não Freqüentes diariamente & & 111 \\
\hline TOTAL & & $\mathbf{2 5 0}$ \\
\hline
\end{tabular}

Fonte: Elaborada pelos autores.

No entanto, uma das características da Associação é atender bem todas as crianças e jovens. Os funcionários e voluntários demonstram vontade de se organizar, no entanto a quantidade de funcionários é insuficiente para atender à demanda atual e a Associação apresenta muitas fragilidades em seus controles internos, como mostra no Quadro 5.

Quadro 5 - Controles Internos existentes e ausentes na Associação

\begin{tabular}{|c|c|}
\hline CONTROLES EXISTENTES & CONTROLES AUSENTES \\
\hline Controle de Estoque Gêneros Alimentícios & Controle de Estoque de Materiais de Consumo e Material \\
\hline
\end{tabular}


A Adoção dos Controles Internos em uma Organização do Terceiro Setor como Sustentabilidade Econômica:...

\begin{tabular}{|l|l|}
\hline & Didático \\
\hline Controle das Contas a pagar & $\begin{array}{l}\text { Controle Orçamentário; Controle de Projeção de Custos, } \\
\text { gastos com crianças e jovens }\end{array}$ \\
\hline Controle da conta Caixa & Controle de Doações (Recebimentos) \\
\hline $\begin{array}{l}\text { Controle Tributário (Realizado somente pela } \\
\text { Contabilidade terceirizada) }\end{array}$ & Controle do Imobilizado \\
\hline & Conciliação \\
\hline & Técnicas de Análise de Investimento \\
\hline & Análise das Demonstrações Contábeis \\
\hline
\end{tabular}

Fonte: Elaborada pelos autores.

Observou-se que, dentro das fragilidades encontradas, uma delas é a ausência do setor de compras na Associação, pois, quando necessita da compra de algum material, este é solicitado à "secretaria/administração", onde é repassado para a diretora executiva realizar a aprovação.

A ausência dos controles internos afeta o resultado da Associação. Devido a esse fato, muitas informações não são passadas para a Contabilidade realizar os registros. Quando a Associação ganha um recurso em espécie ou um imobilizado (como, por exemplo, um computador, o que ocorreu no período em que foi feita a pesquisa), estes não são registrados. Controlar o imobilizado evita possíveis extravios de bens da Associação e contribui para que ela tenha conhecimentos dos seus bens úteis e também dos bens obsoletos.

Um controle de estoque dos materiais de consumo e materiais didáticos seria interessante para a organização não se deparar com a surpresa de que não há material para realizar as atividades. Esse fato já ocorreu na organização por falta de controle.

Ter uma projeção orçamentária é essencial para controlar os gastos com as crianças e jovens e identificar o custo de cada atividade a ser oferecida a eles. Isso é imprescindível para a Associação. Além disso, o orçamento contribui para que a organização realize um planejamento. Permite que a Associação conheça suas despesas, podendo identificar as despesas altas e, muitas vezes, as despesas desnecessárias.

A técnica de investimento e análise das demonstrações contábeis não se aplica à Associação que ainda não apresenta os relatórios contábeis com regularidade. A Associação precisa mudar essa cultura de que os relatórios são apenas necessários no momento de prestação de contas aos órgãos públicos. A Associação encontra-se em fase de expansão, construindo ambientes para realizar mais oficinas e atender a mais crianças e jovens, contudo, é preciso melhorar os seus controles internos para que os recursos recebidos sejam bem empregados e tenham menos desperdício.

O sistema de controle existente na Associação (Controle de Estoque de Gênero Alimentício; Controle de Contas a Pagar; Controle da Conta Caixa; Controle Tributário) contribuem para a sustentabilidade econômica da mesma. Por meio do controle de estoque de gênero alimentício, a Associação evita desperdício de alimentos que estragam por perderem a sua validade. Isso é um ganho para as crianças e jovens que são amparados pela Associação. O controle de contas a pagar também beneficia todos os envolvidos, uma vez que a Associação não paga multa e juros por motivo de desorganização e esquecimento das datas de pagamento. Além disso, esse controle permite que a administração faça os seus planejamentos e tenha sempre condições de honrar com os seus compromissos financeiros. O controle da conta caixa é fundamental para evitar fraude e erros na entrada e saída de recursos monetários. O controle tributário refere-se ao controle das declarações acessórias, em que a 
Associação é obrigada a prestar contas, uma vez que Associação possui isenções da maioria dos impostos. Esse controle é importante para que a organização esteja com a documentação atualizada favorecendo a renovação de convênios com a prefeitura e demais órgãos que solicitam as declarações acessórias como requisito para a continuidade dos convênios e parcerias.

Apesar de a Associação possuir esses controles (Controle de Estoque de Gênero Alimentício; Controle de Contas a Pagar; Controle da Conta Caixa; Controle Tributário), o sistema de controle ainda é insuficiente, uma vez que a ausência dos controles mencionados no Quadro 5 propicia o espaço para fraudes e desvios na organização.

Os resultados encontrados neste estudo, apesar de não poder serem generalizados, são semelhantes em muitos aspectos com as pesquisas empíricas publicadas pelos autores: Albuquerque (2011); Azevedo, Ensslin e Reina (2010); Lunkes (2008). Todos esses estudos demonstram que os controles internos ainda não são suficientes para atender à gestão e precisam ser aprimorados ou aplicados quando constatada a sua ausência. A presença dos controles internos na organização é fundamental para sua sustentabilidade econômica. Este estudo demonstrou que os controles internos existentes contribuem para a Associação agregar valor, evitando descontinuidade de convênios, erros, fraudes e aumentando o potencial informativo, conforme ressaltado por Pereira (2004). No entanto, a ausência de outros controles internos desfavorece a sustentabilidade econômica.

\section{Considerações Finais}

O estudo realizado cumpriu o objetivo proposto de verificar a contribuição do sistema de controles internos para a sustentabilidade econômica de uma Associação de apoio a crianças e jovens no estado de Minas Gerais. Os controles internos implicam melhores resultados para a Associação, uma vez que reduz erros e fraudes.

Uma limitação desta pesquisa está no fato de ter tido uma visão do controle no foco antifraude, poderia ter explorado melhor o foco em gestão, como apresentado por Pereira (2004). A tendência é o crescimento da relevância dos controles internos para a gestão, com a criação de relatórios internos que apresentem planejamento das atividades de rotinas e estratégias. As organizações do Terceiro Setor devem ter uma atenção maior para a qualidade nos processos de gestão. Com a escassez de recursos financeiros e mão de obra, a instituição deve se atentar aos controles internos para melhorar os processos de sua gestão.

Verificou-se que os objetivos específicos desta pesquisa também foram atingidos. Foi feita uma análise da estrutura organizacional e das atividades desenvolvidas pela Associação; um diagnóstico em relação à necessidade de Controles Internos visando à sustentabilidade econômica e um confronto com os controles internos existentes. Por meio desse levantamento foi possível verificar que existem alguns controles internos dentro da Associação, porém alguns controles que poderiam fortalecer a sustentabilidade da Associação não foram encontrados. Esses controles internos ausentes oferecem margem a fraudes, erros e desperdícios dos recursos físicos e financeiros, afetando a sustentabilidade econômica da Associação se tais fatos forem concretizados.

Conclui-se que é visível a importância da adoção dos controles internos para obter um bom desempenho na gestão da Associação e na salvaguarda dos seus bens. Verificou-se que a Associação necessita adotar controles internos para as entradas de doações; para a 
movimentação de materiais de consumo e materiais didáticos; para o levantamento do imobilizado existente na organização. Além disso, a Associação precisa realizar conciliações das suas contas "caixa e bancos". A adoção de um orçamento, de técnicas de investimento e de análise das demonstrações contábeis também deve ser implementada para obtenção de melhores resultados. Contudo, é essencial a apresentação das demonstrações contábeis e as prestações das contas regularmente para que estas sejam usadas para tomada de decisões e não apenas para mostrar aos órgãos públicos. Com isso, será possível aperfeiçoar os controles da gestão da Associação, melhorar o aproveitamento dos recursos públicos e doações recebidas, apresentar uma transparência das atividades desenvolvidas e consequentemente alcançar a sustentabilidade econômica da Associação.

Essa pesquisa contribui para destacar a relevância dos controles internos em organizações do Terceiro Setor, instigando mais investigações sobre o assunto. Sugere-se que sejam feitas pesquisas sobre os controles internos em diversas organizações do Terceiro Setor, sem se prender em apenas um estudo de caso. Tais pesquisas podem mostrar o cenário das organizações a respeito dos controles internos, estimulando descobrir quais os fatores facilitadores e dificultadores para a implementação desses controles nas organizações do Terceiro Setor.

\section{Referências}

ALBUQUERQUE, J. M. Avaliação dos controles internos de uma instituição pública de ensino superior à luz da metodologia MCDA-Construtivista. Revista Contemporânea de Contabilidade, v. 8, n. 15, p. 129-150, jan.-jun. 2011.

ALMEIDA, M. C. Auditoria: Um Curso Moderno e Completo. 6. ed. São Paulo: Atlas, 2008. ANTHONY, R. N; GOVINDARAJAN, V. Sistemas de Controle Gerencial. 12. ed. São Paulo: McGraw Hill, 2008.

ASSAF NETO, A. Finanças Corporativas e Valor. 4. ed. São Paulo: Atlas, 2009.

ATTIÊ, W. Auditoria Interna. 2. ed. São Paulo: Editora Atlas, 2007

AZEVEDO, N. K.; ENSSLIN, S. R.; REINA, D. R. M. Controle Interno e as Fundações de apoio à pesquisa universitária: uma análise do funcionamento do Controle Interno nas Fundações da Universidade Federal de Santa Catarina no ano de 2010. Enfoque: Reflexão Contábil, v. 29, n. 3, p. 34-45, set./dez. 2010.

CONSElHO FEDERAL DE CONTABILIDADE. Manual de Procedimentos Contábeis e Prestação de Contas das Entidades de Interesse Social. Conselho Federal de Contabilidade. $2^{\mathrm{a}} \quad$ Reimpressão. Brasília, 2008. Disponível em: <http://www.cfc.org.br/uparq/Livro_manual_fund.pdf>. Acesso em 16 de maio de 2011.

FARIAS, R. P.; LUCA, M. M. M., MACHADO, M. V. V. A metodologia COSO como ferramenta de gerenciamento dos controles internos. Contabilidade, Gestão e Governança Brasília, v. 12, n. 3, p. 55-71, set./dez. 2009.

FISCHER, R. M. Estado, Mercado e Terceiro Setor: uma análise conceitual das parcerias intersetoriais. Revista de Administração, São Paulo, v. 40, n. 1, p. 5-18, jan./fev./mar. 2005. 
Disponível em: <http://www.cyta.com.ar/biblioteca/bddoc/bd_articles/ 334_fis.pdf>. Acesso em 16 de maio de 2011.

O desafio da colaboração: praticas de responsabilidade entre empresas e Terceiro Setor. São Paulo: Gente, 2002.

FRANCO, H.; MARRA, E. Auditoria contábil: Normas de Auditoria Procedimentos e Papéis de Trabalho, Programas de Auditoria, Relatórios de Auditoria. São Paulo: Atlas, 2004.

GITMAN, L. J. Princípios de Administração Financeira. 10. ed. São Paulo: Pearson Prentice Hall, 2004.

LOPES de SÁ, A. L. Curso de Auditoria. 10. ed. São Paulo: Atlas, 2002.

LUNKES, R. J. O Uso de Controles Internos: Um Estudo em Empresas Hoteleiras. Revista de Contabilidade da UFBA, v. 2, n. 3, p. 50-66 set./dez. 2008.

MARION, J. C. Contabilidade básica. 7. ed. SãoPaulo: Atlas, 2004.

MARTIN, N. C. Da Contabilidade à Controladoria: a Evolução Necessária. Revista de Contabilidade e Finanças da USP, São Paulo, Ano XIII, N. 28, p. 7-28, jan./abr. 2002.

MARTIN, N. C.; SANTOS, L. R. dos; DIAS FILHO, J. M. Governança empresarial, riscos e controles internos: a emergência de um novo modelo de controladoria. Revista de Contabilidade e Finanças da USP, São Paulo, v. 15, n. 34, abr. 2004.

MATARAZZO, D. C. Análise financeira de Balanços: abordagem básica e gerencial. 6. ed. São Paulo: Atlas, 2003.

MATTOS, C. de C.; MARIANO, R. P. Controle interno: Uma abordagem teórica. Contabilidade Vista e Revista, v. 15, n. 3, p. 27-44, dez. 1999.

MIGLIAVACCA, P. N. Controles internos nas organizações: fraudes, corrupção, ineficiências. 2. ed. São Paulo : Edicta, 2004.

OLIVEIRA, L. M.; CHIEREGATO, R.; PEREZ JR., J. H.; GOMES, M. B. Manual de Contabilidade Tributária. 9. ed. São Paulo: Atlas, 2010.

OLIVEIRA, L. S. Tratado de Metodologia Cientifica, Projetos de Pesquisas, TGI, TCC, Monografias, Dissertações e Teses. São Paulo: Pioneira Thomson Learning, 2004.

PADOVEZE, C. L. Contabilidade Gerencial: um enfoque em sistema de informação contábil. 4. ed. São Paulo: Atlas, 2004.

PASCOAL, J. A. Gestão Estratégica de Recursos Materiais: controle de estoque e armazenagem. 2008.1. 61p. Monografia (Graduação em Administração) Centro Universitário de João Pessoa - UNIPÊ. Disponível em: <http://unipe.br/blog/administracao/wpcontent/uploads/2008/11/gestao-estrategica-de-recursos-materiais-controle-de-estoque-earmazenamento.pdf>. Acesso em 16 de maio de 2011.

PEREIRA, A. N. Controles internos empresariais e gestão: Visões e importância - Uma abordagem exploratória. Contabilidade Vista e Revista, v. 15, n. 3, p. 27-44, dez. 2004.

PEREZ JR., J. H. Auditoria de Demonstrações Contábeis: normas e procedimentos. São Paulo: Atlas, 2006. 
SALVATORE, V. L. O. Desafios das entidades sociais na busca da identidade. São Paulo, Federação de Obras Sociais, Mimeo, 1998.

SILVA, W. A. C.; ROCHA, A. M.; MELO, A. A. O. Sistema de Gerenciamento e Controle Interno: uma Análise dos Escritórios de Contabilidade de Belo Horizonte/MG e Região Metropolitana a partir da Taxonomia de Kaplan e Cooper. Revista de Contabilidade e Organizações, vol. 5, n. 11, p. 125-144, 2011.

SILVA MAIA, M., RIBEIRO DA SILVA, M.; DUEÑAS, R., PLAZA DE ALMEIDA, P., MARCONDES, S., YUH CHING, H. Contribuição do sistema de controle interno para a excelência corporativa. Revista Universo Contábil, v.1, n. 1, p. 54-70, jan./abr., 2005.

VALADÃO JR., V. M.; MALAQUIAS, R. F.; SOUSA, E. G. Controladoria como uma opção à sustentabilidade econômica nas organizações de Terceiro Setor: o caso de uma associação. Revista Contemporânea de Contabilidade. Ano 5. v. 1, n. 9, p. 131-151, jan./jun. 2008.

VERGARA, S. C. Projetos e relatórios de pesquisa em administração. 3. ed. São Paulo: Atlas, 2000. 


\section{ANEXO 1}

\section{ROTEIRO DE ENTREVISTA}

\section{Roteiro (Diretoria Executiva)}

1) Como surgiu a Associação (Saber um pouco da história).

2) Na fundação da Associação foi feito um planejamento para o seu funcionamento? Se sim, quais foram os tipos de planejamento?

3) Atualmente quantos funcionários a Associação possui?

4) A Associação possui um manual interno explicando quais são as atribuições e responsabilidades dos funcionários e da diretoria?

5) A Associação possui um código de ética ou de conduta dos funcionários?

6) A Associação é dividida em departamentos, seções ou atividades? Como funciona? Existe um responsável para fazer as compras e outro para controlar o almoxarifado? (Explique).

7) As atribuições e responsabilidades das atividades (departamentos) estão claramente definidas para os funcionários?

8) A Associação realiza reuniões frequentes com os funcionários? Essas reuniões acontecem somente com os diretores?

9) A Associação proporciona treinamento aos funcionários?

10) A Contabilidade da Associação é terceirizada ou interna? Que tipos de controle os funcionários elaboram? Existe Auditoria Interna na Associação?

\section{Roteiro (Área Administrativa)}

1) Ao realizar compras (materiais de consumo, alimentação e imobilizado) é feita uma cotação de preços? Como funciona? Quantos fornecedores são consultados?

2) Existe segurança de que somente as compras efetivamente recebidas são liberadas para pagamento? Considere: o funcionário, antes de liberar a nota fiscal para pagamento, confere o documento fiscal (incluindo somas, multiplicações, etc.) com ordem de compra ou contrato e inspeciona evidência do recebimento dos bens ou da prestação do serviço? 
3) A empresa elabora orçamento referente à despesa de compra de materiais e bens do imobilizado, etc.? Se sim, os valores incorridos são comparados com os orçados, sendo analisadas as variações anormais e/ou significativas?

4) A Associação possui controle de estoque de gênero alimentício? E controle dos bens patrimoniais da Associação? Quais os controles internos existentes?

5) Os pedidos de compras são formalizados? Quem autoriza realizar as compras? Para realizar compras, passa-se primeiro para uma autorização? É verificada a especificação do pedido? Verifica-se a qualidade deste material ou imobilizado a ser comprado?

6) É feita cotação de preços junto aos fornecedores, a fim de obter as melhores condições comerciais?

7) Qual a responsabilidade de cada departamento na Associação? Quais são os controles internos utilizados nos departamentos?

8) Quais são os softwares ou sistemas utilizados na Associação? Estes softwares possuem ferramentas de controles?

\section{Roteiro (Área Financeira)}

1) A empresa elabora controles financeiros ou gerenciais? Controle dos custos? Controle de caixa?

2) A empresa utiliza um manual de Contabilidade (estrutura das contas, quando cada conta deve ser debitada e creditada, modelos padronizado das demonstrações contábeis, relatórios gerenciais internos e as práticas contábeis utilizadas) a fim de permitir o registro ordenado e consistente de suas transações?

3) Quais os controles existentes na Associação:

( ) Conciliação Bancária

( ) Controle de Tributos

( ) Orçamentos

( ) Controle de Contas a receber

( ) Controle do Imobilizado

( ) Controle de Custos

( ) Controle de Gênero Alimentício

Outros Controles Existentes:
( ) Controle de Contas a pagar
( ) Controle de Folha de Pagamento
( ) Controle de Obrigações Acessórias
- ( ) Controle de Doações
( ) Análise das Demonstrações Contábeis
( ) Controle de Estoques de Materiais
( ) Técnica de Análise de Investimento

4) $O$ contador da Associação orienta nas questões referentes às prestações de contas, demonstrativos e investimentos (orçamento, por exemplo, de uma reforma)?

5) Funcionários já encontraram erro no contracheque (recibo)? Se sim, que tipos de erros? 
6) A Associação possui um caixa para realizar despesas pequenas? Como funciona? Qual o valor médio que fica em caixa?

7) A Contabilidade elabora conciliações bancárias em base mensal (poderia detectar um recebimento não depositado ou até mesmo omissão ou erro de contabilização?

8) A Associação conta com software na área financeira? Se sim, explique se o software possui ferramenta de controle. 